\title{
Seed preferences of Pyrrhocoris apterus (Heteroptera: Pyrrhocoridae): Are there specialized trophic populations?
}

\author{
Marta KRISTENOVÁ, Alice EXNEROVÁ and Pavel ŠTYS \\ Department of Zoology, Charles University Prague, Viničná 7, CZ 12844 Prague, Czech Republic; \\ e-mail: marta.hauznerova@seznam.cz
}

Key words. Heteroptera, Pyrrhocoridae, Pyrrhocoris apterus, feeding duration, feeding behaviour, trophic population, seed preferences, Tilia platyphyllos, Althaea officinalis, Robinia pseudacacia

\begin{abstract}
The populations of the firebug Pyrrhocoris apterus (Heteroptera: Pyrrhocoridae) in Europe exhibit three kinds of host plant associations: feeding on seeds of (1) Tilia spp. (Tiliaceae), (2) Malvaceae (s. str.), and (3) Robinia pseudacacia (Fabaceae). The three host plant taxa often grow in different habitats and localities. We have tested the hypothesis that $P$. apterus forms on different host plants specialised "trophic populations" which also influence its food preference. We have collected $P$. apterus from localities with Tilia platyphyllos, Malva neglecta or Robinia pseudacacia as host plants and tested their preferences in a multiple choice test involving seeds of Tilia cordata, T. platyphyllos, Althaea officinalis, Alcea rosea and Robinia pseudacacia. The original host plant of $P$. apterus population had no influence on food preferences. However, the preferences differed between adults and the third instar larvae. The adults preferred seeds of Robinia pseudacacia followed by Althaea officinalis, while the preferences of larvae were less pronounced and ranked in order Althaea officinalis, Robinia pseudacacia, and Tilia platyphyllos. Existence of trophic populations of $P$. apterus was not confirmed by our experiment. Durations of feeding were longer on preferred species of seeds in both adults and larvae.
\end{abstract}

\section{INTRODUCTION}

The firebug, Pyrrhocoris apterus (L., 1758) (Heteroptera: Pentatomomorpha: Pyrrhocoridae), is a common, gregarious, Palaearctic species occurring also in fringing parts of the Afrotropical and Oriental regions. It was also introduced to North America, but it has not been collected there since 1896 (Barber, 1911; Massee, 1954; Henry, 1988; Kerzhner, 2001). The species is phytophagous and pterygodimorphic, and it is being used in a variety of morphological, developmental, ecological, ethological, physiological (mainly endocrinological), biochemical, genetic and evolutionary studies (reviewed by Socha, 1993). Because of its striking red-and-black coloration, the firebug and its differently pigmented mutants are nowadays commonly used in studies of aposematism (e.g. Exnerová et al., 2006). The Central European populations consist largely of brachypterous, non-flying individuals while the less frequently occurring and also non-flying macropters function as a "dispersal morph" (Socha \& Zemek, 2003).

The majority of phytophagous insects is oligophagous, being associated with a few closely related plant species, or species similar in one or more critical attributes such as biochemistry, properties of epidermis, life form and habitat (Ward et al., 2003; Milanović \& Gliksman, 2004; Notman \& Villegas, 2005). There are two extreme views concerning the host plants of Pyrrhocoris apterus. Many European authors believe that it is mainly associated with seeds of linden trees (Tilia spp.), which are also used as a major food source in its cultures. However, P. apterus was observed feeding on seeds and other parts of many plant species of the families Asparagaceae, Asteraceae (esp. Helianthus annuus), Betulaceae, Boraginaceae, Cornaceae, Cupressaceae, Fabaceae (including Robinia pseudacacia and Caragana arborescens), Fagaceae, Lamiaceae, Malvaceae (s. str.), Rosaceae, Sapindaceae, Tiliaceae and Ulmaceae. Consequently this bug is also believed to be widely polyphagous (Massee, 1954; Lipowa \& Lipa, 1957; Tischler, 1959; Schlagbauer, 1966; Puchkov, 1974; Pluot, 1978; Ahmad \& Schaefer, 1987; Korcz, 1994; Stehlík \& Heiss, 2000). The former, Tiliacentred view is undoubtedly overly limited, and results probably from conspicuousness of large aggregations of $P$. apterus on or under linden trees, which also provide the most easily available hibernacula in Europe. The latter, "polyphagous" view, probably also does not correspond to the true situation, because it takes into account many observations of accidental feeding on trophically non-essential plant species.

According to field observation in Czech Republic and Slovakia, the firebug regularly feeds on seeds and reproductive organs of three host-plant groups, namely (a) Tiliaceae (currently included in Malvaceae; Judd et al., 2002) - Tilia cordata (native), T. platyphyllos (native), T. tomentosa (of Balkan origin; widely planted) and their hybrids, (b) Malvaceae (s. str.) - genera Althaea (A. officinalis), Malva (M. neglecta, M. sylvestris and undoubtedly others), Alcea (A. rosea, A. biennis), genus Hibiscus (H. syriacus) and (c) Robinia pseudacacia (Fabaceae). These host plants may grow together at the same locality or in exclusive enclaves (Tilia stands in mixed woods, flowerbeds of planted species of Malvaceae in gardens and parks, planted or invasive Robinia woods). Species of the genus Tilia are probably the most 
common host plants in Central Europe, mainly growing in the woods, planted in parks and alleys, or as isolated trees. Various species of Malvaceae (s. str.) (herbs as well as shrubs and trees) are major host plants of Pyrrhocoris apterus in the Mediterranean (Honěk, 1987; P.Š., A.E. long-term observations) where the linden trees are often missing. The association of $P$. apterus with Malvaceae (s. str.) in Central Europe is particularly frequent in gardens, waste places and xerothermic biotopes. The locust tree, Robinia pseudacacia, grows (and had formerly been planted) in the Central Europe, and its seeds are often the only source of food in planted woods on lowland sandy or alluvial soils. The trophic association of $P$. apterus with Robinia pseudacacia is strange since the plant originated in North America, was planted in Europe for the first time in France as early as 1601, and the first record from Czech Republic is from 1710 (Slavík, 1995). Moreover, the plant is generally unpalatable to European insects.

It is unknown whether $P$. apterus prefers seeds of some of its host plants on which it is feeding from the young larval instars up to the adult stage, or whether it is just exploiting any of them at random. The small populations of $P$. apterus in enclaves in which only one kind of its host plants grows (Tilia $\times$ herbaceous Malvaceae $\times$ Robinia) may be quasi-permanent, lasting for many generations and to a certain degree isolated. We therefore ask whether they have a specific affinity to their host plants or just opportunistically use what is suitable and available. In the former case we would call them specialized trophic populations. The aim of this study is to find out (1) whether Pyrrhocoris apterus is just utilizing any available seeds of a suitable host plant without a distinct preference, or (2) whether there is a specific preference influencing the food choice, and (3) in the latter case, whether such a preference depends on the original host plant. Chemical defence of phytophagous true bugs may depend on the host plant on which they feed (Tullberg et al., 2000). Knowledge of food requirements of natural populations of a species feeding on several discrete groups of host plants with potentially different levels of toxicity is particularly important for species like Pyrrhocoris apterus, which are used as models in a variety of experimental studies. It is generally believed that host plant ranges of larvae of the phytophagous true bugs are more restricted than those of the adults. We have found a first explicit formulation of this rule by Puchkov (1956) but it is self-evident: the adults are better equipped for dispersal, may encounter more suitable plant species and engage also in feeding on facultative host plants. Therefore, we have compared the seed preferences in adults and the third instar larvae that already engage in seed feeding (Puchkov, 1974).

Out of the four feeding mechanisms found in phytophagous true bugs (Schaefer \& Panizzi, 2000), Pyrrhocoridae use the lacerate-and-flush method, in which the bugs repeatedly thrust their stylets back and forth until a number of cells has been broken down, and then flush out the seed content with a flow of saliva (Miles, 1972; Cob- ben, 1978; Backus, 1988; Schaefer \& Panizzi, 2000). Since this feeding method requires usually a considerable amount of time, the actual duration of feeding may vary among different kinds of host plant seeds. We have tested whether the feeding duration in adults and in the third instar larvae was affected (1) by the species of seeds, and (2) by the original host plant at which the founders of laboratory cultures of $P$. apterus were collected.

\section{MATERIAL AND METHODS}

\section{Pyrrhocoris apterus}

Brachypterous adults of Pyrrhocoris apterus were collected over the territory of Prague, Central Bohemia, Czech Republic from three localities of Robinia pseudacacia $\left(50^{\circ} 8^{\prime} \mathrm{N}, 14^{\circ} 24^{\prime} \mathrm{E}\right)$, Tilia platyphyllos $\left(50^{\circ} 8^{\prime} \mathrm{N}, 14^{\circ} 22^{\prime} \mathrm{E}\right)$ and Malva neglecta $\left(50^{\circ} 5^{\prime} \mathrm{N}, 14^{\circ} 22^{\prime} \mathrm{E}\right)$.

At each locality only one species of the host plant was available, and occurred there for at least three years (Malva neglecta) to several decades (Robinia pseudacacia, Tilia platyphyllos). All the larval instars as well as adults of $P$. apterus were always present and feeding on the host plant. The localities chosen were about $200 \mathrm{~m}$ distant from those with different host plants to prevent chance dispersal and they allowed for hibernation. Groups of Pyrrhocoris apterus differing by locality and original host plant were used for establishment of laboratory cultures (hereafter called "host-plant groups"). The cultures were maintained on a diet of seeds of Robinia pseudacacia, Tilia platyphyllos and Althaea officinalis, respectively, and water. The minute seeds of Malva neglecta were replaced by those of Althaea officinalis since the former cannot be picked up in field and are not commercially available. The genera Alcea and Althaea are closely related to Malva, the species Alcea rosea and Althaea officinalis are widely planted in gardens of Prague, and often function as supplementary host plants. Both the species, regardless whether native or escaped, are host plants of $P$. apterus (A.E. and P.S. ., pers.obs.) in the Mediterranean; the same is true for Prague gardens. Consequently, the opportunistic switch to their seeds in cultures and experiments is legitimate, and the population will be regarded as coming from Althea officinalis hereafter.

The other cultures were reared on species of seeds corresponding to their original host plants. Therefore, in the case of existence of trophic populations, our laboratory cultures would have the same preferences as $P$. apterus from original localities. New (laboratory born F1) generations of the third instar larvae and adults were used for testing. P. apterus in cultures was reared at temperature of $25^{\circ} \mathrm{C}$ and $14 \mathrm{~L}: 10 \mathrm{D}$ photoperiod.

\section{Seeds}

In our experiments we used dry ripe seeds of Alcea rosea (average size $-5 \mathrm{~mm}$ in diameter), Althaea officinalis (2 $\mathrm{mm}$ ), Tilia cordata $(5 \mathrm{~mm})$, Tilia platyphyllos $(10 \mathrm{~mm})$ and Robinia pseudacacia $(6 \mathrm{~mm})$. Seeds of Robinia pseudacacia, Tilia cordata and Tilia platyphyllos were collected in field, those of Alcea rosea and Althaea officinalis were purchased from commercial suppliers. The seeds were offered intact, only those of Tilia platyphyllos offered to larvae were cracked, because the larval stylets cannot penetrate their thick pericarp (Honěk, 1987).

\section{Experimental design}

Preference of seeds in multiple-choice experiments

Pyrrhocoris apterus was offered a multiple choice among the seeds of Alcea rosea, Althaea officinalis, Tilia cordata, Tilia platyphyllos, and Robinia pseudacacia. We simultaneously pre- 
TABLE 1. Counts of adult Pyrrhocoris apterus originating from three host-plant groups that preferred particular species of seed in multiple-choice experiment. Thirty individuals from each host-plant group were tested.

\begin{tabular}{lccccc}
\hline & \multicolumn{5}{c}{ Preferred seeds } \\
\cline { 2 - 6 } Host-plant group & $\begin{array}{c}\text { Tilia } \\
\text { cor- } \\
\text { data }\end{array}$ & $\begin{array}{c}\text { Tilia } \\
\text { platy- } \\
\text { phyllos }\end{array}$ & $\begin{array}{c}\text { Althaea } \\
\text { offici- } \\
\text { nalis }\end{array}$ & $\begin{array}{c}\text { Alcea } \\
\text { rosea }\end{array}$ & $\begin{array}{c}\text { Robinia } \\
\text { pseud- } \\
\text { acacia }\end{array}$ \\
\hline Tilia platyphyllos & 4 & 0 & 5 & 0 & 21 \\
Althaea officinalis & 0 & 0 & 13 & 0 & 17 \\
Robinia pseudacacia & 1 & 0 & 13 & 0 & 16 \\
\hline
\end{tabular}

sented five seeds of each species, but six seeds of Althaea officinalis, a species with the smallest seeds.

To standardize their feeding motivation, adults were starved for seven and larvae for three days prior to the experiment. At the beginning of the experiment, an individual of $P$. apterus was placed in a Petri dish ( $9 \mathrm{~cm}$ diameter) with all the seeds grouped in the centre. Behaviour of Pyrrhocoris apterus was observed for $60 \mathrm{~min}$, and the seed handling and duration of feeding was recorded. The seed was scored as preferred, when it was the first choice, and the bug was feeding on it for at least $30 \mathrm{~min}$. This limit was set according to observations that feeding lasting less than 30 min frequently results in abandoning the seed and an immediate attempt to suck on another one. Such short initial attempts were classified as abandoned choices of unsuitable seeds. The realized feeding was characterised by insertion of the stylets into the seed followed by rhythmic movements of the labium (Socha et al., 1998) accompanied also by rhythmic movements of the antennae. If the individual did not feed during the experiment at all, it was tested again after 48 hours. We have tested 30 adults and 30 third instar larvae originating from each of the three host-plant groups (Robinia, Tilia, Alcea).

\section{Duration of feeding}

Part of the feeding duration measurements was taken during multiple-choice experiments. In this case the feeding of $P$. apterus was not interrupted after the period of the multiplechoice experiment $(60 \mathrm{~min})$ has elapsed. To measure the duration of feeding on non-preferred seeds and also to get sufficient number of measurements, other $P$. apterus individuals were offered only one kind of seeds. Again, only feeding lasting at least 30 min was taken into account. Since P. apterus (both larvae and adults) usually refused to suck on non-preferred kinds of seeds, we have obtained a sufficient number of measurements only for seeds of Althaea officinalis, Tilia platyphyllos, and Robinia pseudacaci (not for Alcea rosea and Tilia cordata). Each $P$. apterus individual was used only once. In total, we have measured the feeding durations of ten adults and ten third instar larvae from each of the three host-plant groups (Robinia, Tilia, Alcea) for each species of seed.

\section{Data analysis}

Data from food preference experiments were expressed as counts of the individuals from different host-plant group (represented by laboratory cultures) that preferred a particular species of seeds. Resulting contingency tables were subjected to loglinear analysis to test whether food preferences of the bugs were independent on their host plants, and whether the third instar larvae preferred the same seeds as adults.

We used Nested design ANOVA to compare durations of feeding between the different species of seeds and between the different host-plant groups. Feeding duration was a response variable; host-plant group and species of seed were factors, with species of seed nested in host-plant group. We applied Fisher
TABLE 2. Counts of the third instar larvae of Pyrrhocoris apterus originating from three host-plant groups that preferred particular kind of seed in multiple-choice experiment. Thirty individuals from each host-plant groups were tested.

\begin{tabular}{lccccc}
\hline & \multicolumn{5}{c}{ Preferred seeds } \\
\cline { 2 - 6 } Host-plant group & $\begin{array}{c}\text { Tilia } \\
\text { cor- } \\
\text { data }\end{array}$ & $\begin{array}{c}\text { Tilia } \\
\text { platy- } \\
\text { phyllos }\end{array}$ & $\begin{array}{c}\text { Althaea } \\
\text { offici- } \\
\text { nalis }\end{array}$ & $\begin{array}{c}\text { Alcea } \\
\text { rosea }\end{array}$ & $\begin{array}{c}\text { Robinia } \\
\text { pseud- } \\
\text { acacia }\end{array}$ \\
\hline Tilia platyphyllos & 0 & 9 & 12 & 0 & 9 \\
Althaea officinalis & 0 & 3 & 19 & 0 & 8 \\
Robinia pseudacacia & 0 & 6 & 15 & 0 & 9 \\
\hline
\end{tabular}

LSD post-hoc tests for pairwise comparisons between levels of the factors tested.

All calculations were performed by using STATISTICA software; all the p-values mentioned are two-tailed.

\section{RESULTS}

\section{Seed preference}

Individuals originating from different host-plant groups did not differ significantly in their food preferences (adults: $\chi^{2}=7.58$, d.f. $=8, p=0.48$; larvae: $\chi^{2}=8.19$, d.f. $=8, \mathrm{p}=0.42$ ). In other words, the species of seeds $P$. apterus were reared on as well as host plants at the localities where founders of laboratory cultures were collected did not influence their present food preferences. Therefore, we pooled the data from the three host-plant groups to compare preferences of the third instar larvae and adults, males and females, and to test whether the counts of individuals that preferred various species of the seeds differ from chance.

Adults and the third instar larvae had different food preferences $\left(\chi^{2}=35.19\right.$, d.f. $\left.=4, p<0.01\right)$. Counts of adults that preferred various species of seed differed from chance $\left(\chi^{2}=124.00\right.$, d.f. $\left.=4, \mathrm{p}<0.01\right)$. The adults preferred seeds of Robinia pseudacacia $(60 \%$ of tested individuals), followed by Althaea officinalis (34.4\%), and by Tilia cordata $(5.6 \%)$. Not a single individual preferred Alcea rosea and Tilia platyphyllos (Table 1). We have found no difference between seed preferences of males $(\mathrm{n}=43)$ and females $\left(\mathrm{n}=47 ; \chi^{2}=0.85\right.$, d.f. $=4, \mathrm{p}=$ 0.93).

Counts of the third instar larvae that preferred various species of seeds differed from chance $\left(\chi^{2}=83.00\right.$, d.f. $=4, \mathrm{p}<0.01)$. Larvae preferred seeds of Althaea officinalis (51.1\%), followed by Robinia pseudacacia $(28.9 \%)$, and Tilia platyphyllos $(20 \%)$. Not a single individual preferred Alcea rosea and Tilia cordata (Table 2).

\section{Duration of feeding}

Origin of adults from a particular host-plant group had no effect on feeding duration on a particular species of their seed (Nested design ANOVA: $\mathrm{F}_{2,81}=2.71, \mathrm{p}=0.07$; Fig. 1). The feeding duration was, however, affected by the species of seed $\left(\mathrm{F}_{6,81}=4.62, \mathrm{p}<0.01\right.$; Fig. 1). The adults sucked longer on seeds of Althaea officinalis (mean $284.5 \mathrm{~min}$ ) and Robinia pseudacacia (mean 254 min) than on seeds of Tilia platyphyllos (mean 186.8 $\mathrm{min}$ ), but the pairwise comparisons were significant only 


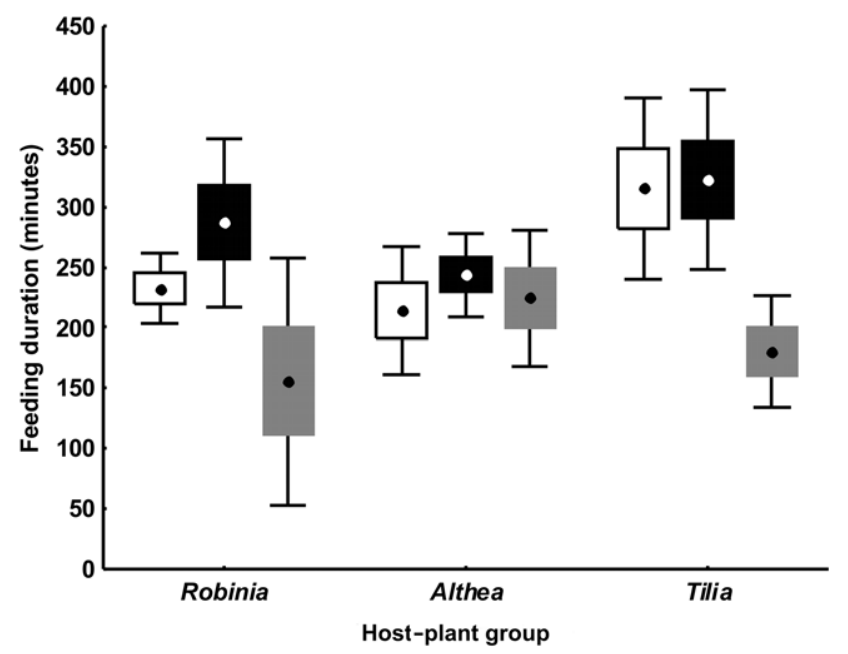

Fig. 1. Feeding durations of adult Pyrrhocoris apterus originating from three host-plant groups (Robinia pseudacacia, Althaea officinalis and Tilia platyphyllos) on seeds of Robinia pseudacacia (white boxes), Althaea officinalis (black boxes) and Tilia platyphyllos (grey boxes). Ten P. apterus were tested in each combination. Points - means, boxes - standard errors, whiskers $-95 \%$ confidence intervals.

in populations coming from Robinia pseudacacia and Tilia platyphyllos (Fisher LSD tests: $\mathrm{p}<0.05$ in all comparisons).

In the third instar larvae, the feeding duration was significantly influenced by the host-plant group to which the larvae belonged (Nested design ANOVA: $F_{2,81}=7.74$, $\mathrm{p}<0.01$; Fig. 2). Larvae reared on Robinia pseudacacia sucked significantly longer on all species of seeds than larvae from the other two cultures (Fisher LSD tests: $\mathrm{p}<0.01$ in both comparisons). The feeding duration of the third instar larvae was also influenced by the species of seed (Nested design ANOVA: $\mathrm{F}_{6,81}=2.90, \mathrm{p}=0.01$; Fig. 2). The larvae sucked longer on the seeds of Althaea officinalis (mean $163.9 \mathrm{~min}$ ) and Robinia pseudacacia (mean $144 \mathrm{~min}$.) than on seeds of Tilia platyphyllos (mean $93.3 \mathrm{~min}$ ), but the pairwise comparisons were significant only in cultures reared on Robinia pseudacacia and Althea officinalis (Fisher LSD tests: $\mathrm{p}<0.05$ in all comparisons).

\section{DISCUSSION}

\section{Seed preferences}

Seed preferences of the firebugs were not influenced by the original host plant that the adults and the third instar larvae came from. Therefore there is no evidence to believe in existence of specialised trophic populations and our original hypothesis was not confirmed. The firebugs are apparently quite versatile in their food choice, and even isolated populations living on a particular host plant are able to switch easily to another, preferred or more readily available food. The versatility of their food choice may help firebugs to colonize new localities even when their dispersal abilities are limited by their inability to fly.

The adult firebugs preferred seeds of Robinia pseudacacia $(60 \%)$ over those of Althaea officinalis (34\%); Tilia cordata was preferred by the rest $(6 \%)$. The prefer-

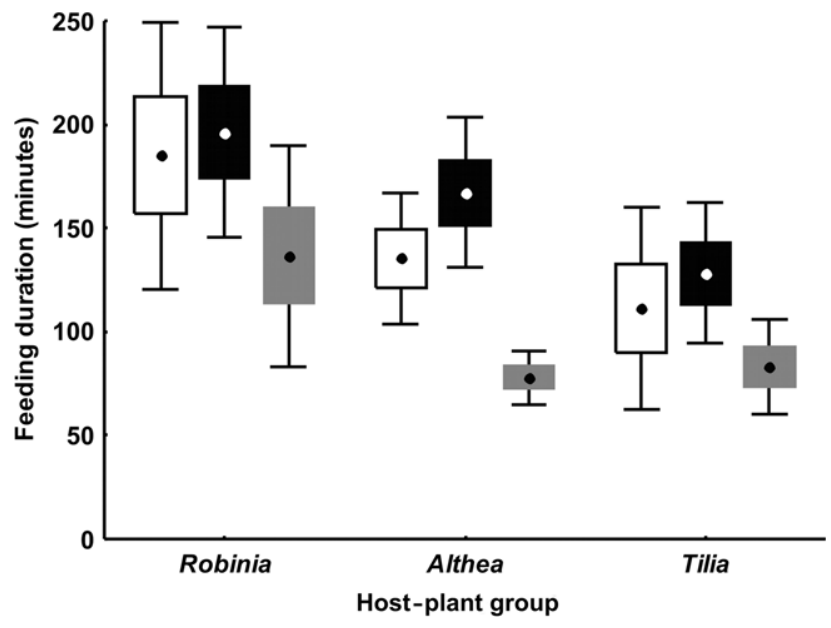

Fig. 2. Feeding durations of the third instar larvae of Pyrrhocoris apterus originating from three host-plant groups (Robinia pseudacacia, Althaea officinalis and Tilia platyphyllos) on seeds of Robinia pseudacacia (white boxes), Althaea officinalis (black boxes), and Tilia platyphyllos (grey boxes). Ten P. apterus were tested in each combination. Points - means, boxes - standard errors, whiskers $-95 \%$ confidence intervals.

ences of larvae were somewhat different and more widespread: Althaea officinalis (51\%), Robinia pseudacacia $(29 \%)$ and Tilia platyphyllos (20\%). Tischler (1959) also noticed that laboratory reared firebugs preferred seeds of the Malvaceae (s. str.) against those of Tilia. These preferences cannot presently be explained phytochemically, nutritionally or by mechanical properties of the seeds. However, we offer a few comments. Pyrrhocorris apterus can certainly overcome strong phytochemical defences since it may complete its life cycle on seeds of trees that are generally avoided by phytophagous insects (Tilia, Robinia). For instance, the firebug is resistant to farnesol, contained in Tilia seeds, that exerts a juvenoid effect on other insects (Sláma, 1969); the firebug can apparently overcome the effects of allelopathic chemicals of Robinia as well. It is remarkable how quickly the firebug has exploited resources of this deuterochthonous tree present in Europe for just about 400 years, although it has never adapted to the native European species of Fabaceae (with the exception of the Sino-Siberian shrub Caragana arborescens widely planted in the Ukraine (Puchkov, 1956). However, Pyrrhocoris apterus reared on seeds of Robinia pseudacacia has shorter lifespan then those reared on seeds of Tilia spp. or various Malvaceae (Hauznerová, 2003). An obvious advantage to live and feed on Robinia pseudacacia and Tilia spp. is avoidance of competition for seeds with other insects. The order of preference by the third instar firebug larvae has two complementary explanations. The sequence Althaea officinalis - Robinia pseudacacia - Tilia platyphyllos corresponds to the increasing thickness of the seed pericarp (though the linden seeds have been cracked in the experiments), and the penetration of a thicker pericarp by stylets of firebug larvae should last longer. Moreover, the firebug inhabits basically an extensive southern belt of the Palaearctic (excl. non-maghrebian part of Africa and 
the Far East) and Pakistan, including extensive treeless areas, and we may hypothesize that the herbaceous Malvaceae (s. str.) are its original host plants. The readiness of the firebugs to accept a number of diverse malvaceous herbs as host plants also supports this hypothesis. Since the larvae of the phytophagous species of Heteroptera are more conservative than the adults in their food choice, the larval preference for the autochthonous Althaea over a recently invaded and taxonomically distant Robinia makes sense.

\section{Feeding duration}

Feeding durations may be affected by many factors, whose influence may depend on the feeding method of a particular heteropteran species. Unfortunately, comparative data on feeding durations are scarce, because majority of food preference studies have concentrated on survival and reproduction of bugs reared on different diets (for review see Schaefer \& Panizzi, 2000).

Feeding durations of the adult firebugs were not influenced by the host-plant group. Surprisingly, the third instar larvae from Robinia pseudacacia host-plant group were feeding longer on all species of seeds than the larvae from the other two host-plant groups. Feeding durations on different species of seeds in the adults and in the third instar larvae followed the same pattern. The firebugs were feeding for longer periods on seeds of Althaea officinalis and Robinia pseudacacia than on those of Tilia platyphyllos (seed size $10 \mathrm{~mm}$ ). These results cannot be interpreted by different seed sizes - feeding durations on 2 $\mathrm{mm}$ seeds of Althea officinalis and on $6 \mathrm{~mm}$ seeds of Robinia pseudacacia were closely similar. The differences in feeding durations may be associated with the seed preferences - longer feeding durations were measured on the preferred species of seeds (Robinia pseudacacia and Althea officinalis). Positive correlation between food preference and feeding duration was found in Nezara virudula (Pentatomidae) feeding on green and red tomato fruits (Lye \& Story, 1988). On the contrary, Ventura et al. (2000) found no correlation between seed preference and feeding duration in Neomegalotomus parvus (Alydidae) feeding on seeds of several species of leguminous plants (Fabaceae). Generally, we can suggest several reasons that affect duration of feeding on a modal seed of a particular plant species, viz (a) palatability of the seed, (b) amount and concentration of nutrients, (c) amount or concentration of secondary metabolites, (d) efforts required for penetration of the pericarp and/or laceration and sucking the liquefied seed material. Without more detailed inquiry it is impossible to assess the significance of longer vs. shorter duration of sucking: e.g., the long duration may indicate flow of highly concentrated nutrients and achievement of a full satiation on one hand, but also slow and long-lasting extraction of a stuff of poor nutritive value. The same is true in reverse for short duration of sucking.

ACKNOWLEDGEMENTS. The study was supported by Czech Science Foundation (project 206/07/0507) and Ministry of Education (project 0021620828). Our thanks are due to two anonymous reviewers for considerable improvement of our paper.

\section{REFERENCES}

Ahmad I. \& Schaefer C.W. 1987: Food plants and feeding biology of the Pyrrhocoroidea (Hemiptera). Phytophaga 1: 75-92.

BACKUS E. 1988: Sensory systems and behaviours which mediate hemipteran plant-feeding: a taxonomic overview. $J$. Insect Physiol. 34: 151-165.

Barber H.G. 1911: Pyrrhocoris apterus Linn. in the United States. J. N. Y. Entomol. Soc. 19: 111-112.

Cobben R.H. 1978: Evolutionary Trends in Heteroptera. Part II Mouthpart-structures and Feeding Strategies. Veenman \& Zonen, Wageningen, 407 pp.

Exnerová A., Svádová K., Štys P., Barcalová S., Landová E., Prokopová M., Fuchs R. \& Socha R. 2006: Importace of colour in the reaction of passerine predators to aposematic prey: experiments with mutants of Pyrrhocoris apterus (Heteroptera). Biol. J. Linn. Soc. 88: 143-153.

HAUZNEROVÁ M. 2003: Food preference of the firebug. Živa 51: 281-282 [in Czech].

Henry T.J. 1988: Family Pyrrhocoridae Fieber, 1860. In Henry T.J. \& Froeschner R.C. (eds): Catalogue of the Heteroptera, or True Bugs, of Canada and the Continental United States. Brill, Leiden, pp. 613-615.

HonĚK A. 1987: Regulation of body size in a heteropteran bug, Pyrrhocoris apterus. Entomol. Exp. Appl. 44: 257-262.

Judd W.S., Campbell C.S., Kellogg E.A., Stevens P.F. \& Donoghue M.J. 2002: Plant Systematics. A Phylogenetic Approach. 2nd ed. Sinauer Associates, Sunderland, MA, 576 pp.

Kerzhner I.M. 2001: Family Pyrrhocoridae Amyot \& Serville, 1843. In Aukema B. \& Rieger C. (eds): Catalogue of Heteroptera of the Palearctic Region. Vol. 4. The Netherlands Entomological Society, Amsterdam, pp. 248-258.

Korcz A. 1994: Firebug - pest or useful insect? Ochrona Roslin 38: 6-7 [in Polish].

Lipowa I. \& Lipa J.J. 1957: Observation of the firebug's (Pyrrhocoris apterus L.) feeding behaviour and its host plants. Biul. Inst. Ochr. Rosl. 2: 199-206 [in Polish].

Lye B. \& Story R.N. 1988: Feeding preference of the southern green stink bug (Hemiptera: Pentatomidae) on tomato fruit. $J$. Econ. Entomol. 81: 522-526.

Massee A.M. 1954: In search of Pyrrhocoris apterus (L.) (Hem., Pyrhocoridae) in Devonshire. Entomol. Mon. Mag. 90: 45-46.

Milanović D. \& Gliksman I. 2004: Selection responses and quantitative-genetic analysis of preadult performance on two host plants in the been weevil, Acanthoscelides obtectus. Entomol. Exp. Appl. 113: 125-133.

Miles P.W. 1972: The saliva of Hemiptera. Adv. Insect Physiol. 9: $183-225$.

Notman E.M. \& Villegas A.C. 2005: Patterns of seed predation by vertebrate versus invertebrate seed predators among different plant species, seasons and spatial distributions. In Forget P.M, Lambert J.E, Hulme P.E. \& Vander Wall S.B. (eds): Seed Fate. Predation, Dispersal and Seedling Establishment. CABI, Wallingford, pp. 55-75.

Pluot D. 1978: Données sur Scantius aegyptius, Hémiptère Pyrrhocoride paléarctique, comparaison avec Pyrrhocoris apterus. Ann. Soc. Entomol. Fr. 14: 703-713 [in French].

PuchKov V.G. 1956: Essential trophic groups of the phytophagous Heteroptera and changes in the kind of their feeding during development. Zool. Zh. 35: 32-44 [in Russian].

Puchkov V.G. 1974: Berytidae, Pyrrhocoridae, Piesmatidae, Aradidae, Tingidae. Fauna Ukraini. Vol. 21. Naukova Dumka, Kiiv, 332 pp. [in Ukrainian]. 
Schaefer C.W. \& Panizzi A.R. (eds) 2000: Heteroptera of Economic Importance. CRC Press LLC, Boca Raton, FL, 828 pp.

Schlagbauer A. 1966: Eine Methode zur Massen- und Dauerzucht der Feuerwanze, Pyrrhocoris apterus Linnaeus. Beitr. Entomol. 16: 199-202 [in German].

SLÁmA K. 1969: Plants as a source of materials with insect hormone activity. Entomol. Exp. Appl. 12: 721-728.

Slaví B. 1995: Flora of the Czech Republic. Vol. 4. Academia, Praha, 529 pp. [in Czech].

SochA R. 1993: Pyrrhocoris apterus (Heteroptera) - an experimental model species: A review. Eur. J. Entomol. 90: 241-286.

Socha R. \& Zемeк R. 2003: Wing morph-related differences in the walking pattern and dispersal in a flightless bug, Pyrrhocoris apterus (Heteroptera). Oikos 100: 35-42.

Socha R., Šula J. \& ZemeK R. 1998: Feeding behaviour, digestive physiology and lipid content in macropterous females of Pyrrhocoris apterus (L.) (Heteroptera: Pyrrhocoridae). Physiol. Entomol. 23: 91-96.
Stehlík J.L. \& Heiss E. 2000: Results of the investigations on Hemiptera in Moravia made by the Moravian Museum (Aradidae, Pyrrhocoridae). Acta Mus. Mor. Sci. Biol. 85: 333-350.

Tischler W. 1959: Zur Biologie der Feuerwanze (Pyrrhocoris apterus L.). Zool. Anz. 163: 392-396 [in German].

Tullberg B.S., Gamberale-Stille G. \& Solbreck C. 2000: Effect of food plant and group size on predator defence: differences between two co-occurring aposematic Lygaeinae bugs. Ecol. Entomol. 25: 220-225.

Ventura M.U., Montalván R. \& Panizzi A.R. 2000: Feeding preferences and related types of behaviour of Neomegalotomus parvus. Entomol. Exp. Appl. 97: 309-315.

Ward L.K., Hackshaw A. \& Clarke R.T. 2003: Do food-plant preferences of modern families of phytophagous insects and mites reflect past evolution with plants? Biol. J. Linn. Soc. 78: 51-83.

Received January 24, 2011; revised and accepted April 21, 2011 